\title{
Changes of chemical reactions in soil during electric processing by means of UV-radiation
}

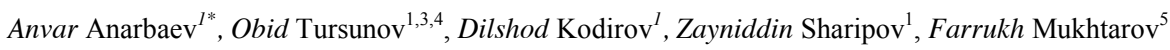 \\ ${ }^{1}$ Tashkent Institute of Irrigation and Agricultural Mechanization Engineers, 100000 Tashkent, Uzbekistan \\ ${ }^{2}$ Institute of Energetic Problems, Uzbek Academy of Science, 100084 Tashkent, Uzbekistan \\ ${ }^{3}$ Research Institute of Forestry, 111104 Tashkent, Uzbekistan \\ ${ }^{4}$ Gulistan State University, 120100 Gulistan, Uzbekistan \\ ${ }^{5}$ Tashkent State Technical University, 100097 Tashkent, Uzbekistan
}

\begin{abstract}
The technology of electro-processing by UV-radiation soil of agricultural plants is considered. The mechanism of the effect of UV irradiation to change by redox reactions a chemical potential of the soil is shown. As the result of experimental researches, optimum parameters for processing soils with ultraviolet radiation lamps for increasing the absorption of the most mobile manganese forms in plants are defined.
\end{abstract}

\section{Introduction}

Investigations of chemical equilibria are given the most important place in the physical chemistry of soils [1-3]. Among the problems associated with the problem of equilibria is the prediction of the directions of chemical reactions occurring in soils, which are closely related to the thermodynamics of soil solutions and surface phenomena [4-6].

A change in the composition and amount of dissolved substances causes a change in the chemical potential of water. The difference in the chemical potentials of water containing a solute can increase movement in the root system of a plant [7-8]. This will improve the metabolism of nutrients in the plant cells.

Information on the photochemical properties of soils upon exposure to UV radiation is fragmentary. It is known [9] that under the influence of ultraviolet light, colored organic substances are capable of attaching oxygen even in molecular form. This is directly related to the biological activity and soil fertility, because the humus contains amino acids that can inhibit the activity of soil enzymes. This photomethylation changes the number of functional groups, which affects the colloidal-chemical properties of humus.

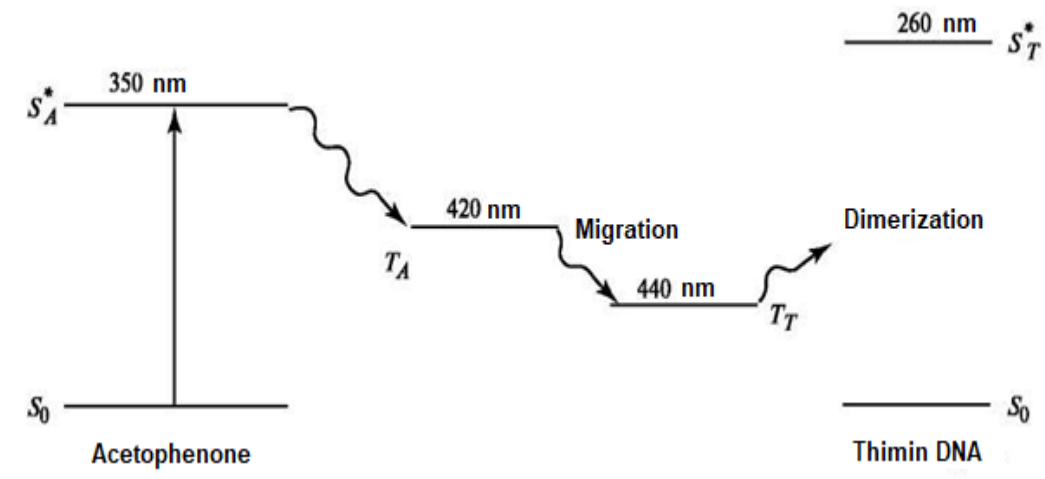

Fig. 1. Scheme of excitation of plant cells when exposed to ultraviolet radiation

The plant is very sensitive to the wavelength of ultraviolet radiation. In Fig. 1, the values of the energies of the levels are given in the wavelengths of quanta of the corresponding energy. When a DNA solution in acetophenone is irradiated with light with a wavelength of $350 \mathrm{~nm}$, quanta are absorbed only by the sensitizer [10].

Redox reactions in soils occur in a complex environment in a multiphase environment with poorly soluble compounds [11]. Along with purely chemical processes in soils, biochemical processes of oxidation and reduction are widely developed. In practice, oxidation is considered as a reaction in which oxygen is added to a substance, or electrons are lost by a substance.

The ability of the soil to undergo redox reactions can be measured using the redox potential.

${ }^{*}$ Corresponding author: anizan6004@mail.ru 


\section{Research Methods}

The magnitude of the osmotic pressure depends on the composition of the solution and temperature [12]; the relationship between it and the activity of water in solution is expressed most simply by $\pi$

$$
-R \cdot T \cdot \ln a_{w}=\int_{\pi}^{p+\pi} v_{w} d p
$$

here $p$ - hydrostatic pressure; $\pi$ - osmotic pressure; $v_{w}$ - molar volume of water, $R$-gas constant, $T$-temperature. Due to the weak compressibility of water, the integral on the right can be replaced by a difference. With a molecular weight of water equal to $0.018 \mathrm{~kg} / \mathrm{mol}[13]$

where $d$ is the density of the solution, $\mathrm{kg} / \mathrm{m}^{3}$.

$$
\pi=-\frac{R T \cdot d}{0,018} \ln a_{w}
$$

For arid soil solutions (from the Latin aridus "dry", or desert climate), and semiard (steppe) regions, where the system $\mathrm{Ca}, \mathrm{Mg}, \mathrm{Na} \| \mathrm{Cl}$, SO4- $\mathrm{H}_{2} \mathrm{O}$ water activity can be calculated using the expression [14]

$$
\ln a_{w}=-0,018 \cdot I \cdot \sum_{j=1}^{N} \frac{v_{j}}{p_{j}} \eta_{j} \times\left\{1+\ln 10\left[\frac{v_{j}+v_{j-}}{v} \cdot I\left(b_{j}^{0}+\sum_{k=2}^{N} \alpha_{j k}^{0} \cdot y_{k}\right)-\left|z_{j}+z_{j-}\right| A \sqrt{I} \sigma\left(r_{j}^{0} \cdot B \sqrt{I}\right)\right]\right\}
$$

$A$ - the value of the ionic strength associated with the different number of electrons in the reaction.

The electrical conductivity EC of these solutions closely correlates with the value of the osmotic pressure of soil solutions, so, according to [15], the root-mean-square error of the formula was $15 \% . E_{c}=23,4 \pi$

Since the activities of the substances (activity coefficients) participating in the reaction are unknown, we will use the concentration form of the Nernst equation [16] with the substitution of the apparent standard redox potential $E^{0}$ as a constant:

$$
E=E^{0}+\frac{2,303 \cdot R \cdot T}{n \cdot F} \cdot \lg \frac{[O x]}{[\operatorname{Red}]}
$$

The quantity $\frac{2,303 \cdot R \cdot T}{n \cdot F}$ for brevity, denoted by the symbol $\vartheta$. In general, the redox potential is a complex function of the activities of various oxidized and reduced forms of substances involved in the reaction [17]. With the participation of hydrogen ions in the reaction, their activity also affects the value of the redox potential.

\section{Results}

The system $\mathrm{MnO}_{4}-\Leftrightarrow \mathrm{Mn}^{2+}$ was chosen as a typical example for calculations. In this case, the reaction proceeds with the participation of eight hydrogen ions [18]:

$$
\mathrm{MnO}_{4}^{-}+8 \mathrm{H}^{+}+5 e \Leftrightarrow \mathrm{Mn}^{2+}+4 \mathrm{H}_{2} \mathrm{O}
$$

The magnitude of the oxidative potential is determined in this case by the equation

$$
\begin{gathered}
E=E^{0}+\frac{\vartheta}{5} \lg \frac{a_{M n O_{4}^{-}} \cdot a_{H^{+}}^{8}}{a_{M n^{2+}}}=E^{0}+\frac{\vartheta 8}{5} \lg a_{H^{+}}+\frac{\vartheta}{5} \lg \frac{a_{M n o_{4}^{-}}}{a_{M n^{2+}}}= \\
=E^{0}-\frac{\vartheta 8}{5} p H+\frac{\vartheta}{5} \lg \frac{a_{M n O_{4}^{-}}}{a_{M n^{2+}}}
\end{gathered}
$$

at $18^{0} \mathrm{C}: E=E^{0}-0,0923 \cdot p H+0,0115 \cdot \lg \frac{a_{M n O_{4}^{-}}}{a_{M n^{2+}}}$

Manganese compounds also form other redox systems. Solid state manganese dioxide is reduced to $\mathrm{Mn}^{2+}$ :

$$
\mathrm{MnO}_{2(\mathrm{~ms})}+4 \mathrm{H}^{+}+2 e \Leftrightarrow \mathrm{Mn}^{2+}+2 \mathrm{H}_{2} \mathrm{O}
$$

then $E=E^{0}+\frac{\vartheta}{2} \lg \frac{\left(a_{H^{+}}\right)^{4}}{a_{M^{2+}}}$, since the activity of manganese dioxide in the solid phase is taken to be unity.

According the known ongoing reaction based on the values of normal oxidation potentials in determining the amount of divalent manganese in the soil

$$
E=0,991+0,0581 \sqrt{\Gamma}-0,116 p H-0,029 \lg \left[\mathrm{Mn}^{2+}\right]
$$

Table 1. Normal potentials of a number of redox soil systems

\begin{tabular}{|l|c|c|c|c|}
\hline $\begin{array}{c}\text { Element } \\
\text { symbol }\end{array}$ & Highest oxidation state & $+n \cdot e^{-}$ & Lowest oxidation state & $E^{0}, \mathrm{~V}$ \\
\hline $\mathrm{Cu}$ & $\mathrm{Cu} 2+$ & $+2 \cdot e^{-}$ & $\mathrm{Cu} \downarrow$ & +0.345 \\
\hline & $\mathrm{Cu} 2+$ & $+e^{-}$ & $\mathrm{Cu}$ & +0.159 \\
\hline $\mathrm{Mn}$ & $\mathrm{Cu}(\mathrm{NH} 3) 42+$ & $+e^{-}$ & $\mathrm{Cu}\left(\mathrm{NH}_{3}\right)_{2}^{+}+2 \mathrm{NH}_{3}$ & -0.01 \\
\hline & $\mathrm{Mn}^{3+}$ & $+e^{-}$ & $\mathrm{Mn}^{2+}$ & +0.151 \\
\hline & $\mathrm{Mn}(\mathrm{OH})_{3} \downarrow$ & $+e^{-}$ & $\mathrm{Mn}\left(\mathrm{OH}_{2}+\mathrm{OH}^{-}\right.$ & +0.1 \\
\hline & $\mathrm{Mn}(\mathrm{OH})_{3} \downarrow+3 H^{+}$ & $+e^{-}$ & $\mathrm{Mn}^{2+}+3 \mathrm{H}_{2} \mathrm{O}$ & +1.84 \\
\hline & $\mathrm{MnO} \downarrow+4 \mathrm{H}^{+}$ & $+2 e^{-}$ & $\mathrm{Mn}^{2+}+2 \mathrm{H}_{2} \mathrm{O}$ & +1.23 \\
\hline & $\mathrm{MnO}_{4}^{-}$ & $+e^{-}$ & $\mathrm{MnO}_{4}^{2-}$ & +0.558 \\
\hline & $\mathrm{MnO}_{4}^{-}+4 \mathrm{H}^{+}$ & $+3 e^{-}$ & $\mathrm{MnO}_{2} \downarrow+2 \mathrm{H}_{2} \mathrm{O}$ & +1.69 \\
\hline & $\mathrm{MnO}_{4}^{-}+8 \mathrm{H}^{+}$ & $+5 e^{-}$ & $\mathrm{Mn}^{2+}+4 \mathrm{H}_{2} \mathrm{O}$ & +1.51 \\
\hline
\end{tabular}


Table 1 [19] shows the values of the normal potentials of a number of redox systems that are of interest from the point of view of transformation into mobile forms of trace elements in the soil.

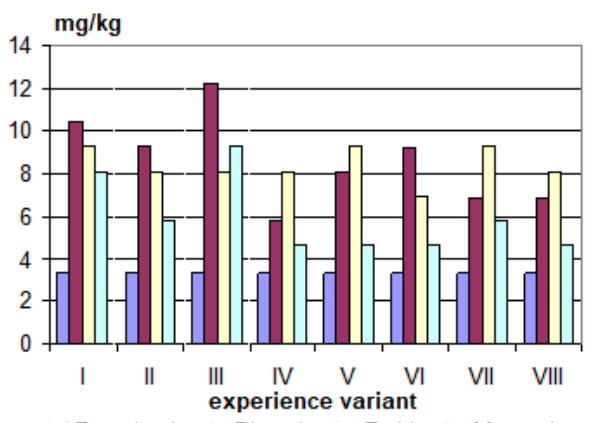

a)

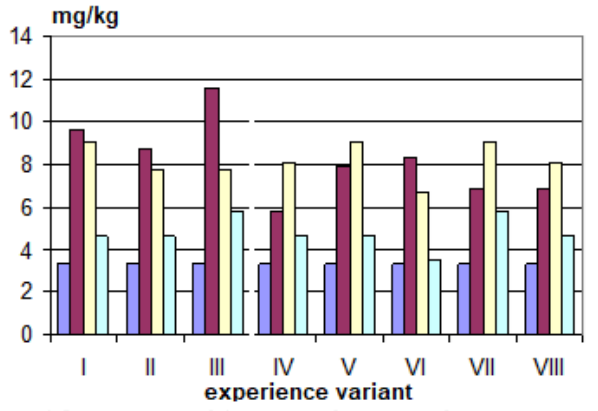

$\square$ Butanization $\square$ Blooming $\square$ Fruiting $\square$ Maturation

b)

Fig. 2. Influence of electrical treatment with UV radiation on the microelement (manganese) composition of the soil by the phases of development (in mg Mn per kg of soil) a) at a depth of the arable layer $0 \div 30 \mathrm{~cm} \mathrm{~b}$ ) at a depth of the soil horizon of $30 \div 50 \mathrm{~cm}$ : I control (soil without plants and UV treatment), II - control (soil with a plant and without UV treatment), III - UV treatment of soil without plants, IV - UV treatment of soil and cotton seeds, V - pre-sowing UV treatment of soil and cotton seeds, soil during sowing, VI - UV treatment of soil and plants during their growing season, VII - UV treatment of soil during plant growing season, VIII - presowing UV treatment of cotton seeds + UV treatment of soil and plants during the growing season of plants

Ultraviolet soil treatment is able to influence the oxidation-reduction processes in the soil in terms of preserving the mobile forms of microelements in it [20-22]. This is shown by the results of experiments on seed treatment carried out in the experimental field base of the agricultural enterprise "BMKB-Agromash" (Fig. 2).

Field test results set for the phases of plant development confirm the above models.

As can be seen from Fig. 2, at the initial phase of the appearance of plant buds, there is no change in the amount of manganese under different variants of experiments, which means the duration of redox processes in the soil from 70 to 95 days.

Compared to control measurements, UV treatment of the soil significantly increases the Mn content (variant III).

Due to the achieved electric potential in the soil, oxygen is separated from oxide compounds from Mn and forms water molecules with hydrogen. When electro treating cotton seeds and soil with UV radiation (option IV), the microelement composition of the soil (for example, manganese) is minimal. This suggests that it is possible to change the chemical equilibrium of the soil towards the formation of an aqueous solution of $\mathrm{Mn}$, which passes from the soil to the plant.

\section{Conclusions}

It is possible to evaluate the light effect of UV radiation as follows.

The zone of direct penetration of UV radiation into the soil is limited $(5 \div 10 \mathrm{~mm})$. Consequently, the effect of light on soil processes is complex. Among the components in the upper layer of the arable layer, which can be affected by UV radiation, are primarily humic substances that cover solid phase particles with films. UV irradiation allows in formulas $(4 \div 6)$ due to an additional quantum of energy $h v$ lead to an excited state an additional electron $e^{-}$in microelements of the soil, thereby increasing the value of the potential $\mathrm{E}$ to the required values, allowing changing the chemical equilibrium of the soil in the direction of water release. Redox processes ensure the appearance of an aqueous solution of trace elements, which are more actively assimilated by plants. At the same time, their productivity and the quality of the grown fruits increase significantly.

\section{References}

1. K. Tang, W.W. Zhu, W.X. Zhou, Z.X. Yi, N.N. Tu, Research progress on effects of soil pH on plant growth and development, Crop Res. 27, 207-212 (2013)

2. L. Xu, H.P. Dai, L. Skuza, S.H. Wei, The effects of different electric fields and electrodes on Solanum nigrum L. Cd hyperaccumulation in soil, Chemosphere 246, 125666 (2020)

3. F. Shaazizov, D. Shukurov, Physical modeling of the filtration process through the dam base, IOP Conference Series: Materials Science and Engineering 869, 072037 (2020)

4. D.S. Orlov, O.N. Biryukova, N.I. Sukhanova, Organic matter of soils of the Russian Federation, Science, Moscow (1996)

5. A.I. Anarbaev, R.A. Zakhidov, N.I. Orlova, U.A. Tadzhiev, Districting of the territory of Uzbekistan by a complex of meteorological factors affecting the efficiency of solar hot water supply systems, Applied Solar Energy 3, 62-73 (2008) 
6. A. Anarbaev, O. Tursunov, R. Zakhidov, D. Kodirov, U. Vakhidov, E. Bozorov, G. Tuhtaeva, A. Babaev, Determination the installation efficiency of the evaporative air cooling in the greenhouse by temperature-moisture regime, IOP Conf. Series: Earth and Environmental Science 616, 012004 (2020)

7. R.A. Chirakkara, K.R. Reddy, C. Cameselle, Electrokinetic amendment in phytoremediation of mixed contaminated soil, Electrochim. Acta 181, 179-191 (2015)

8. R.R. He, G. Xi, K. Liu, Alleviating effect of extremely low frequency pulsed electric field on drought damage of maize seedling roots, J. Lumin. 188, 441-447 (2017)

9. O.A. Danilchenko, D.M. Grodzinsky, V.N. Vlasov, The value of ultraviolet radiation in the life of plants, Physiology and Biochemistry of Crops, Plants 34, 187-198 (2002)

10. C.J. Pushnik, G.W. Miller, V.D. Jolley, J.C. Brown, T.D. Davis, A.M. Barnes, Influences of ultra-violet (UV) blue light radiation on the growth of cotton. II. Photosynthesis, leaf anatomy, and iron reduction, Journal of Plant Nutrition 10(17), 2283 - 2297 (1987)

11. V. Quagliariello, R.V. Iaffaioli, M. Falcone, G. Ferrari, G. Pataro, F. Donsi, Effect of pulsed electric fields assisted extraction on anti-inflammatory and cytotoxic activity of brown rice bioactive compounds, Food Res. Int. 87, 115-124 (2016)

12. P.M. Huang, Y. Li, M.E. Sumner, Handbook of Soil Sciences: Resource Management and Environmental Impacts, Second Edition ( $2^{\text {nd }}$ ed.), CRC Press, USA (2012)

13. R.R. Avezov, A.I. Anarbaev, R.A. Zakhidov, Modeling of double-circuit solar heat supply systems, Applied Solar Energy 2, 35-40 (2004)

14. Ya.A. Pachepsky, Mathematical models of processes in reclaimed soils, Publishing House of Moscow State University, Moscow (1992)

15. Ya.A. Pachepsky, Mathematical models of physical and chemical processes in soils, Science, Moscow (1992)

16. A.I. Anarbaev, R.A. Zakhidov, Energy efficient and environmentally safed technologies using solar systems, hydrogen fuel cells and gas turbines, Applied Solar Energy 1, 68-72 (2011)

17. J.C.R. Bi, M. Schlaak, E. Siefert, R. Lord, H. Connolly, Alternating current electrical field effects on lettuce (Lactuca sativa) growing in hydroponic culture with and without cadmium contamination, J. Appl. Electrochem. 40, 1217-1223 (2010)

18. M.T. Ricart, C. Cameselle, T. Lucas, J.M. Lema, Manganese removal from spiked kaolinitic soil and sludge by electromigration, Sep. Sci. Technol. 34, 3227-3241 (1999)

19. C. Cameselle, R.A. Chirakkara, K.R. Reddy, Electrokinetic-enhanced phytoremediation of soils: status and opportunities, Chemosphere 93, 626-636 (2013)

20. A. Anarbaev, A. Muxammadiev, S. Umarov, O. Tursunov, D. Kodirov, S. Khushiev, F. Muhtarov, Sh. Muzafarov, J. Izzatillaev, Mobile installations for electro treatment of soils and plants with the use of photovoltaic systems as power supply, IOP Conf. Series: Earth and Environmental Science 618, 012004 (2020)

21. J.W. Dobrowolski, O. Tursunov, O. Pirimov, O.J. Nazarova, Laser Biotechnology for Nutritional Health, Sustainable Environment and Development, IOP Conf. Ser.: Earth Environ. Sci. 614, 012108 (2020)

22. N. Toshpulatov, O. Tursunov, D. Kodirov, G. Kholmuratova, Environmentally friendly technology for the destruction of tobacco mosaic viruses (TMV) from selected species of plants, IOP Conf. Ser.: Earth Environ. Sci. 614, 012133 (2020) 